\title{
Differences of anteroposterior facial dimensions in male and female children on intermediate mixed and early permanent dentition using Cervical Vertebrae Maturation Index
}

\author{
Ica Listania ${ }^{1}$, Sri Kuswandari2², Putri Kusuma Wardani Mahendra²
}

\author{
${ }^{1}$ Clinical Dentistry Magister Program, Faculty of Dentistry Gadjah Mada University, Indonesia \\ ${ }^{2 *}$ Department of Paediatric Dentistry, Faculty of Dentistry Gadjah Mada University, Indonesia
}

\begin{abstract}
Introduction: Cervical vertebrae are one of the indicators for craniofacial bones maturation. Timing of craniofacial bone maturation determined achievement of orthodontic early treatment. Some previous researchers recommended cervical vertebral maturation to assess craniofacial growth. This study was aimed to analyse the differences of anteroposterior facial dimensions in male and female children on intermediate mixed and early permanent dentition using Cervical Vertebrae Maturation Index (CVMI). Methods: An analytic observational study with a cross-sectional design was conducted on the students of Islamic Elementary School (Madrasah Ibtidaiyah) in Depok district, Sleman, Yogyakarta, from July 2019 to January 2020. Subjects consisted of 22 males and 22 females aged 8-11 years, obtained by a consecutive sampling technique. The anteroposterior facial analysis was performed on the lateral cephalometry for measuring the distance of Sella turcica to Nasion (S-N) representing the anterior cranial base, Posterior Nasal Spine to Anterior Nasal Spine (PNS-ANS) representing the maxilla and Gonion-Menton (Go-Me) and Condylion-Gnathion (Co-Gn) represents the mandible. Assessment of CVMI was decided by the Hassel and Farman methods. Data were analysed by One Way ANOVA. Results: The mean value of S-N, PNS-ANS, Go-Me, and Co-Gn dimensions, generally were higher in males than females; however, only dimensions of maxillary and mandibular were showed significant difference $(p<0.05)$, while the $\mathrm{S}-\mathrm{N}$ dimension was not significantly different ( $p>0.05$ ). At the interval of CVMI 3 and 4 , the Go-Me and Co-Gn dimensions showed a significant difference $(p<0.05)$ both in males and females. Conclusion: There was a difference in anteroposterior dimensions of the maxillary and mandibular in cervical vertebral maturation in children with intermediate mixed and early permanent dentition, however, no difference was found in the anterior cranial base.
\end{abstract}

Keywords: Anteroposterior facial dimension; cervical vertebral maturation; intermediate mixed dentition; early permanent dentition

p-ISSN: 1979-0201; e-ISSN: 2549-6212; Available from: http://jurnal.unpad.ac.id/pjd/article/view/30947

DOI: $10.24198 /$ pid.vol33no2.30947

Submission: Sep 19, 2021; Accepted: Nov 29, 2021; Published online: Nov 30, 2021

Corresponding author: Sri Kuswandari, Department of Paediatric Dentistry, Faculty of Dentistry Gadjah Mada University, Indonesia. 1, Jalan Denta, Sleman, Special Region of Yogyakarta, Indonesia, 40132. Phone: +62 852-2812-4344; Email: kuswandarisri@gmail.com 


\section{INTRODUCTION}

Knowledge of craniofacial growth and development is essential in determining the diagnosis, treatment planning, predicting of result, and stability of orthodontic treatment outcomes. ${ }^{1}$ The main issue of orthodontic treatment in developing patients determines the right time to start treatment, especially in the use of functional appliances. Failure to determine the timing of treatment can result in not optimal treatment results. Therefore, dentists need to ascertain a patient's growth status so that proper treatment can be started on time. ${ }^{2}$

Assessment of the level development and somatic maturity of a person is not only based on chronological age but also needs to consider biological age. Biological age can be determined by somatic, sexual, skeletal, and permanent tooth maturation. ${ }^{3}$ There are three skeletal maturity indicators: increased body height, hand and wrist maturation (hand-wrist method), and changes in cervical vertebrae morphology. ${ }^{4,5,6}$ Cervical vertebral maturation can be used as an alternative to the hand-wrist method to assess craniofacial bones. For that, a lateral cephalogram can be used, so additional radiographs are not required. ${ }^{2,7}$ One method to assess cervical vertebral maturation is the Cervical Vertebrae Maturation Index (CVMI) method. The CVMI method exploits an individual's growth potential to identify cervical vertebrae morphology. ${ }^{7,8}$

Some previous researchers recommended cervical vertebral maturation to assess craniofacial growth. Linear measurements of craniofacial to assess anteroposterior growth consisted of anterior cranial base length (S-N), maxillary length (PNSANS), and mandibular length (Go-Me). ${ }^{9}$ A group of researchers has conducted a study to estimate the cranial and mandibular growth during the initial stages of Pubertal Growth Spurt (PGS) by measuring $\mathrm{S}-\mathrm{N}$ to assess the anterior cranial base length and $\mathrm{Co}-\mathrm{Gn}$ to assess the total mandibular length. ${ }^{10,11}$ Other researchers reported that the increased mandibular length was associated with cervical vertebral maturation. , $^{8,12}$

Intensity, onset, and duration of peak craniofacial growth in puberty vary on an individual basis. ${ }^{11}$ Pubertal Growth Spurt can be used for early orthodontic treatment. Several clinical studies had shown that a better and more effective response was obtained when treatment was administered during periods of accelerated growth. ${ }^{13,14}$ Early orthodontic treatment aims to correct or prevent malocclusion, thereby reducing the need to treat more complex permanent teeth. Early orthodontic treatment in children usually can be started in either the primary or mixed dentitions to enhance the dental and skeletal development before the eruption of the permanent dentition. ${ }^{15}$

The dentition phases consist of four periods: early mixed dentition, intermediate mixed dentition, late mixed dentition, and early permanent dentition. ${ }^{4}$ The middle mixed dentition is a tooth period characterized by permanent incisors, and the first molars have fully erupted. On the other hand, all permanent teeth characterize the early permanent dentition in the dental arches (possible presence of second molars, absence of third molars).$^{4}$ In that periods, starting to enter the Pubertal Growth Spurt, females start a growth spurt two years earlier than males. This study was aimed to analyse the differences of anteroposterior facial dimensions in male and female children on intermediate mixed and early permanent dentition using CVMI.

\section{METHODS}

This study was analytic observational with a crosssectional design conducted from July 2019 to January 2020. The subjects of this study were the students of Madrasah Ibtidaiyah in Depok, Sleman Regency, Yogyakarta. The subjects consisted of 22 males and 22 females aged 8-11 years, obtained by a consecutive sampling technique.

Inclusion criteria subjects were as follows: children who had received approval from parents/ guardians to participate in the study by signing informed consent, at least including the category of moderate nutritional status based on WHO-NCHS standards, not previously submitted to orthodontic treatment, in a period of the intermediate mixed dentition and the early permanent dentition, occlusion relations within normal limits, overbite and overjet regular, no crossbite and open bite, no or mild crowding and no extensive proximal caries of the teeth.

In addition, exclusion criteria were as follows: subjects with physical or mental disability, 
subjects with a facial deformity, subjects with bad oral habits, and had a history of chronic disease.

A digital cephalometric radiographs was taken used Vatech with PCH-2500 model specifications, AC power input 100-120 / 200-240 V, $50 / 60 \mathrm{~Hz}, 2.0 \mathrm{kVA}$ (max.) $170 \mathrm{VA}$ (Nominal), according to the operational standards applicable in the Radiology Installation of the Dental and Oral Hospital UGM Prof. Soedomo, Yogyakarta. The obtained lateral cephalometric radiograph was used to assess the cervical vertebrae's maturation and analyze the anteroposterior facial dimensions.

The procedure for assessing cervical vertebral maturation was as follows: the digital cephalometric was viewed using the Microsoft Office Picture Manager program at $100 \%$ magnification and analyzed according to the Hassel and Farman method. The morphology of cervical vertebrae 2 , 3 , and 4 were observed, namely the presence or absence of curvature in the inferior border of the body, the shape of the body, and Intervertebral spacing then compared with the standard of the Hassel and Farman method. There are six stages of Cervical vertebral maturation index (CVMI). In CVMI 1, the inferior border of vertebra bodies C2,
C3, and C4 are flat, with the vertebrae C3 and C4 are wedge-shaped; the superior vertebral borders are tapered from posterior to anterior.

CVMI 2, concavities are developing in the inferior borders of $\mathrm{C} 2$ and $\mathrm{C} 3$; the inferior border of $\mathrm{C} 4$ is flat, and the bodies of $\mathrm{C} 3$ and $\mathrm{C} 4$ are nearly rectangular. CVMI 3 , distinct concavities are seen in the inferior borders of $\mathrm{C2}$ and $\mathrm{C} 3$, whereas a concavity has begun to develop in the inferior border of C4; the bodies of $\mathrm{C} 3$ and $\mathrm{C} 4$ are rectangular.

CVMI 4, distinct concavities are seen in the inferior borders of $\mathrm{C2}, \mathrm{C} 3$, and C4; the vertebral bodies of $\mathrm{C} 3$ and $\mathrm{C} 4$ are becoming more square in shape. CVMI 5, more accentuated concavities are seen in the inferior borders of $\mathrm{C} 2, \mathrm{C} 3$, and $\mathrm{C} 4$; the bodies of $\mathrm{C} 3$ and $\mathrm{C} 4$ are nearly square to square in shape. CVMI 6, deep concavities are seen in the inferior borders of $\mathrm{C} 2, \mathrm{C} 3$, and C4; the bodies of $\mathrm{C} 3$ and $\mathrm{C} 4$ are square or more fantastic in vertical dimension than in horizontal dimension (Fig. 1). ${ }^{8}$

The anteroposterior facial analysis was performed on the lateral cephalometry for measuring the distance of S-N representing the anterior cranial base, PNS-ANS representing the

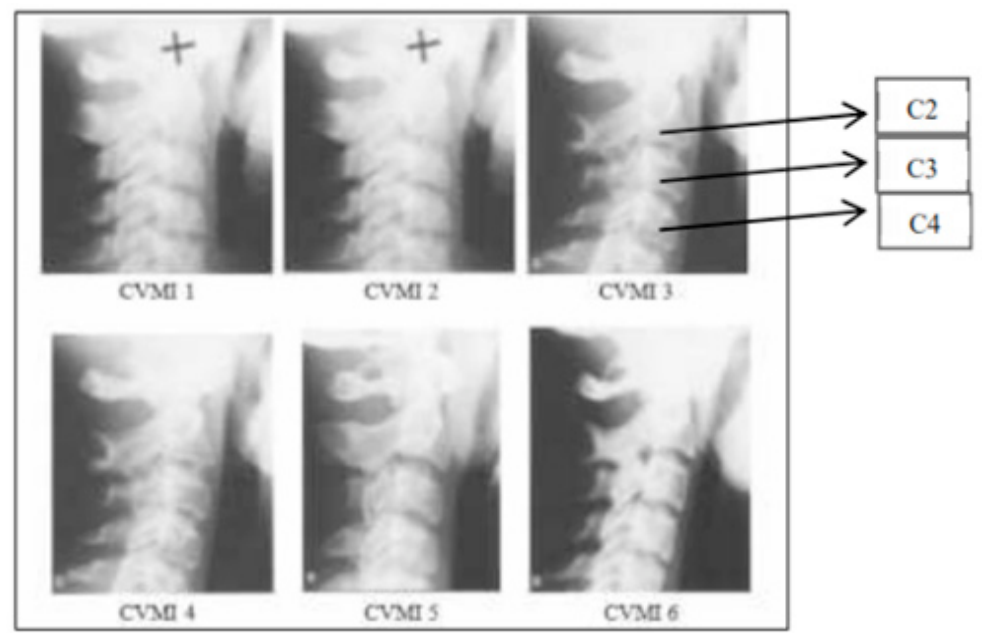

Figure 1. Typical cervical vertebrae appearance using lateral cephalograph ${ }^{8}$

maxilla, and Go-Me and Co-Gn representing the mandible. The digital cephalometric was viewed using the CorelDraw $X 7$ program to adjust the original computer program settings directly connected to the radiographic unit. The digital cephalogram was determined in A4 size, linear size in millimeters. Photo objects locked for the position of the predetermined orientation point did not change when the photo was enlarged or shifted. Cephalogram tracing was performed by determining the orientation points on S, N, PNS, ANS, Go, Me, Co, and $\mathrm{Gn}$; these points were connected to form a linear line according to the parameters. The linear size of each line is noted from the laptop screen. The researcher carried out the reproducibility test by re-analyzing all cephalograms on different occasions to minimize errors. If the initial measurements are within $5 \%$ 
of each other's error distance, then the average of the two will be used.

If the difference is more significant, two additional measurements will be made until the values are within $5 \%$ of each other. All data were tested for normality with the Shapiro-Wilk test and data homogeneity with the Levene test, then analyzed by One-Way ANOVA and Post Hoc Test.

Ethical clearance was obtained from the Research Ethics Commission of the Faculty of Dentistry, Universitas Gadjah Mada prior to the study. Number of Ethical Clearance 00228/KKEP/ FKG-UGM/EC/2019.

\section{RESULTS}

Subjects were divided into three CVMI groups, namely CVMI 2, CVMI 3, and CVMI 4 after a cervical vertebral maturation analysis was carried out. The mean values and standard deviation, Shapiro-Wilk test, Levene test, and One-way ANOVA test of the anterior cranial base (S-N), maxillary (PNS-ANS), and mandibular (Go-Me and Co-Gn) dimensions can be seen in Table 1. The mean values of the anterior cranial base (SN), maxillary (PNS-ANS), and mandibular (Go-Me and Co-Gn) dimensions in the cervical vertebral maturation stage (Table 1) showed higher CVMI 4 than CVMI 3 and CVMI 2 both in male and female.

At CVMI 2, the mean values of $\mathrm{S}-\mathrm{N}$ and Co-Gn dimensions were higher in male subjects, while the mean values of PNS-ANS and Go-Me dimensions were higher in female subjects. At CVMI 3 and CVMI 4, the mean value of the SN, PNS-ANS, Go-Me, and Co-Gn dimensions of male subjects was higher than females, except at CVMI 3 , the mean value of Co-Gn of male subjects was almost the same as for females.

Table 1. Mean values and standard deviation, Shapiro-Wilk test, Levene test, and One-way ANOVA test of the anterior cranial base, maxillary and mandibular dimensions on the cervical vertebrae maturation in male and female subjects

\begin{tabular}{|c|c|c|c|c|c|c|c|c|}
\hline Dimension & Sex & CVMI & $\mathrm{n}$ & $X \pm S D$ & $\begin{array}{c}\text { Shapiro-Wilk } \\
\text { (p) }\end{array}$ & $\begin{array}{l}\text { Levene } \\
\text { (p) }\end{array}$ & $\mathbf{F}$ & $\mathrm{p}$ \\
\hline \multirow{6}{*}{$\mathrm{S}-\mathrm{N}$} & \multirow{3}{*}{$M$} & 2 & 7 & $57.45 \pm 3.00$ & 0.223 & \multirow{3}{*}{0.220} & \multirow{3}{*}{2632} & \multirow{3}{*}{0.098} \\
\hline & & 3 & 8 & $59.09 \pm 2.81$ & 0.227 & & & \\
\hline & & 4 & 7 & $60.62 \pm 1.72$ & 0.433 & & & \\
\hline & \multirow{3}{*}{$\mathrm{F}$} & 2 & 6 & $56.87 \pm 2.32$ & 0.361 & \multirow{3}{*}{0.264} & \multirow{3}{*}{0.296} & \multirow{3}{*}{0.747} \\
\hline & & 3 & 7 & $57.44 \pm 1.86$ & 0.146 & & & \\
\hline & & 4 & 9 & $57.94 \pm 3.28$ & 0.999 & & & \\
\hline \multirow{6}{*}{ PNS-ANS } & \multirow{3}{*}{$M$} & 2 & 7 & $39.68 \pm 3.38$ & 0.359 & \multirow{3}{*}{0.326} & \multirow{3}{*}{$8294^{*}$} & \multirow{3}{*}{$0.003^{*}$} \\
\hline & & 3 & 8 & $42.67 \pm 2.44$ & 0.519 & & & \\
\hline & & 4 & 7 & $45.39 \pm 1.85$ & 0.545 & & & \\
\hline & \multirow{3}{*}{$\mathrm{F}$} & 2 & 6 & $40.00 \pm 1.28$ & 0.332 & \multirow{3}{*}{0.469} & \multirow{3}{*}{$9823^{*}$} & \multirow{3}{*}{$0.001^{*}$} \\
\hline & & 3 & 7 & $41.65 \pm 2.05$ & 0.845 & & & \\
\hline & & 4 & 9 & $44.14 \pm 1.92$ & 0.532 & & & \\
\hline \multirow{6}{*}{ Go-Me } & \multirow{3}{*}{$M$} & 2 & 7 & $55.90 \pm 3.27$ & 0.201 & \multirow{3}{*}{0.280} & \multirow{3}{*}{$15415^{*}$} & \multirow{3}{*}{$0.000^{*}$} \\
\hline & & 3 & 8 & $59.23 \pm 2.16$ & 0.314 & & & \\
\hline & & 4 & 7 & $63.11 \pm 1.60$ & 0.304 & & & \\
\hline & \multirow{3}{*}{$\mathrm{F}$} & 2 & 6 & $56.56 \pm 2.89$ & 0.539 & \multirow{3}{*}{0.866} & \multirow{3}{*}{$8997^{*}$} & \multirow{3}{*}{$0.002^{*}$} \\
\hline & & 3 & 7 & $56.74 \pm 2.84$ & 0.735 & & & \\
\hline & & 4 & 9 & $62.14 \pm 3.13$ & 0.321 & & & \\
\hline \multirow{6}{*}{ Co-Gn } & & 2 & 7 & $89.27 \pm 3.44$ & 0.247 & \multirow{3}{*}{0.304} & \multirow{3}{*}{$17882^{*}$} & \multirow{3}{*}{$0.000^{*}$} \\
\hline & M & 3 & 8 & $92.55 \pm 2.57$ & 0.415 & & & \\
\hline & & 4 & 7 & $98.39 \pm 2.64$ & 0.222 & & & \\
\hline & \multirow{3}{*}{$\mathrm{F}$} & 2 & 6 & $88.35 \pm 3.06$ & 0.577 & & & \\
\hline & & 3 & 7 & $92.57 \pm 1.71$ & 0.069 & 0.463 & $23486^{*}$ & $0.000^{*}$ \\
\hline & & 4 & 9 & $96.20 \pm 1.80$ & 0.685 & & & \\
\hline
\end{tabular}

S-N: distance from the Sella tursica to the Nasion; PNS-ANS: distance from the Posterior Nasal Spine to the Anterior Nasal Spine; Go-Me: distance from the Gonion to the Menton; Co-Gn: distance from the Condylion to the Gnathion; M: Male; F: Female; CVMI: Cervical Vertebrae Maturation Indices; $n$ : number of subjects; $X \pm$ SD: Mean value and standard deviation; $\mathrm{p}$ : probability value; F: F value; *: significance 
The results of the data normality test with the Shapiro-Wilk test (Table 1) showed that the data of the anteroposterior dimension of the anterior cranial base (S-N), maxilla (PNS-ANS), and mandible (Go-Me and Co-Gn) were normally distributed $(p>0.05)$ in male and female subjects, both at CVMI 2, CVMI 3 and CVMI 4. Homogeneity test using the Levene test obtained $p$-value $>0.05$ in all dimensions. The results of the One-Way Anova Test showed that there were significant differences $(p<0.05)$ in the maxillary dimension (PNS-ANS) and mandibular dimensions (Go-Me, Co-Gn) based on cervical vertebral maturation stages 2, 3, and 4, both in male and female subjects. In contrast, a non-significant difference (p> 0.05) was found in the dimensions of the anterior cranial base. The results of the Post Hoc test (Table 2 ) showed that there was no significant difference $(p>0.05)$ in the $\mathrm{S}-\mathrm{N}$ dimension at all CVMI intervals, except for the CVMI 2 and CVMI 4 intervals for male subjects $(p<0.05)$. In the CVMI 2 and CVMI 3 intervals, there were significant differences $(p<0.05)$ in the dimensions of PNSANS, Go-Me, and Co-Gn in male subjects, while in females, only the Co-Gn dimension. In the CVMI 3 and CVMI 4 intervals, there were significant differences in the dimensions of PNS-ANS, Go-Me, and Co-Gn in female subjects, while in males, there were significant differences in Go-Me and Co-Gn dimensions.

Table 2. The results of Post Hoc LSD test in the dimensions of the anterior cranial base (S-N), maxilla (PNS-ANS), and mandible (Go-Me, Co-Gn) based on cervical vertebral maturation stages 2, 3, and 4 in male and female subjects

\begin{tabular}{|c|c|c|c|c|c|c|c|}
\hline \multirow[b]{2}{*}{ Dimension } & \multirow[t]{2}{*}{ Sex } & \multicolumn{2}{|c|}{ CVMI 2 - CVMI 3} & \multicolumn{2}{|c|}{ CVMI 2 - CVMI 4} & \multicolumn{2}{|c|}{ CVMI 3 - CVMI 4} \\
\hline & & $\begin{array}{c}\text { Mean } \\
\text { difference }\end{array}$ & $\mathrm{p}$ & $\begin{array}{c}\text { Mean } \\
\text { difference }\end{array}$ & $p$ & $\begin{array}{c}\text { Mean } \\
\text { difference }\end{array}$ & $\mathrm{p}$ \\
\hline \multirow{2}{*}{ S-N } & $M$ & -1.63714 & 0.236 & -3.17071 & $0.033^{*}$ & -1.53357 & 0.266 \\
\hline & $\mathrm{F}$ & -0.57786 & 0,700 & -1.07444 & 0.452 & -0.49659 & 0.715 \\
\hline \multirow{2}{*}{ PNS-ANS } & M & -2.99152 & $0.040^{*}$ & -5.70714 & $0.001^{*}$ & -2.71563 & 0.060 \\
\hline & $\mathrm{F}$ & -1.65595 & 0.119 & -4.14611 & $0,000^{*}$ & -2.49016 & $0.014^{*}$ \\
\hline \multirow{2}{*}{ Go-Me } & $M$ & -3.3258 & $0.016^{*}$ & -7.20643 & $0,000^{*}$ & -3.88063 & $0.006^{*}$ \\
\hline & $\mathrm{F}$ & -0.17964 & 0.915 & -5.57639 & $0.002^{*}$ & -5.39675 & $0.002^{*}$ \\
\hline \multirow{2}{*}{ Co-Gn } & $M$ & -3.28339 & $0.041^{*}$ & -9.11929 & $0,000^{*}$ & -5.83589 & $0.001^{*}$ \\
\hline & $\mathrm{F}$ & -4.21929 & $0.003^{*}$ & -7.85056 & $0,000^{*}$ & -3.63127 & $0.004^{*}$ \\
\hline
\end{tabular}

S-N: distance from the Sella turcica to the Nasion; PNS-ANS: distance from the Posterior Nasal Spine to the Anterior Nasal Spine; Go-Me: distance from the Gonion to the Menton; Co-Gn: distance from the Condylion to the Gnathion; M: Male; F: Female; CVMI: Cervical Vertebrae Maturation Indices; p: significance value; *: means $p<0.05$

\section{DISCUSSION}

In the intermediate mixed dentition and the early permanent dentition period, males and females begin to experience a growth spurt; early orthodontic treatment is usually performed during this period. Early orthodontic treatment, especially in the use of functional appliances, needs to determine the maturities of the craniofacial bone for the treatment results to be more effective and optimal.

The CVMI method as an indicator of craniofacial bone maturity is used to estimate the Pubertal Growth Spurt period to determine the proper time to start orthodontic treatment. The bones observed in the CVMI method are C2,
C3, and C4, with the advantage that these areas can still be observed even when using a thyroid protective collar during radiation exposure. ${ }^{7,8}$

The results showed that the mean values of the anterior cranial base, maxillary and mandibular dimensions of male and female subjects (Table 1) increased with increasing cervical vertebral maturity. However, most of the mean values of the anterior cranial base, maxillary and mandibular dimensions were higher in the male.

This shows that males growth and development patterns are more significant than female even though craniofacial bones have grown in both of them. ${ }^{1,16}$ Stage of CVMI 2 is accelerated growth, CVMI 3 is transitional, and CVMI 4 is called a deceleration stage or a decrease in growth 
rate. ${ }^{7} \mathrm{~A}$ spike in growth rate that occurs before CVMI 4 is likely to cause the anterior cranial base, maxillary and mandibular dimension at CVMI 4 to be higher than in the previous CVMI. The anterior cranial base at the CVMI 2 and CVMI 3 intervals and the CVMI 3 and CVMI 4 intervals did not show any significant differences in male and female subjects.

This study followed other studies that the $\mathrm{S}-\mathrm{N}$ measurement did not show a significant increase in the initial growth of Pubertal Growth Spurt. ${ }^{17}$ This may be because the anterior cranial base growth is completed earlier, around the age of 8 years, so the anterior cranial base region is relatively stable. ${ }^{18}$

The maxilla showed significant differences in the CVMI 2 and CVMI 3 intervals in male subjects and the CVMI 3 and CVMI 4 intervals in females (Table 2). This shows that the peak of the growth spurt in females occurs earlier than males and that males are more significant than females. ${ }^{1,19}$ The maxilla increases in length due to bone deposition on the posterior of the maxillary tuberosity, which will stimulate forward displacement of the entire maxilla. ${ }^{1}$

The mandible (Go-Me and Co-Gn) showed significant differences in all CVMI intervals in male and female subjects, except for the GoMe dimensions of the female subjects at CVMI 2 and CVMI 3 intervals. The timing variation in the eruption of the mandibular teeth in the female subjects probably caused no significant differences in the Go-Me dimension. The growth of the mandible occurs due to the opposition of the periosteal bone on the posterior edge of the ramus and resorption in the anterior of the ramus. ${ }^{1.16}$

The presence of resorption in the anterior ramus, then the mandibular body increases in length and allows accommodation of the posterior lower teeth. ${ }^{16}$ The eruption of these teeth affects the growth of the alveolar process of the mandible and, together with the growth of the condyles, causes the mandible to increase in height. The posterosuperior growth of the mandibular condylar process will increase the overall anteroposterior dimension of the mandible. ${ }^{1,16}$

In the CVMI 2 and CVMI 3 intervals or between the prepubertal and pubertal phases, the maxillary and mandibular growth (Go-Me, Co-
Gn) was significant in males, whereas, in females, only the mandible (Co-Gn) grew significantly. The results of the other studies indicate that the growth acceleration in the total length of the mandible (Co-Gn) occurs in the pre-peak phase to the peak growth phase of puberty. ${ }^{12}$ In the CVMI 3 and CVMI 4 intervals or pubertal phase, the mandible grows significantly in male and female subjects. In theory, the growth of the mandible grows later than the nasomaxillary complex. ${ }^{1}$ It appears in the results of this study that mandibular growth is still ongoing until the deceleration stage.

The acceleration growth of the mandible at the CVMI 3 and CVMI 4 intervals was following the other study, which showed that the peak of the growth spurt occurs on average between CVM 3 and CVM 4. ${ }^{11}$ Another study was conducted to evaluate changes in mandibular dimensions during five intervals of circumpubertal growth showed that the most significant increase in mandibular length (Co-Gn) occurred during the CS 3 to CS 4 interval $(4.1 \mathrm{~mm}){ }^{20}$

The present study revealed that maxillary and mandibular growth showed significant results. These results differ from the other study, which stated that maxillary and mandibular growth at the acceleration period of growth spurt tends to be linear and affirmed that there is no difference in growth increment during the acceleration and peak stages of the PGS demonstrated by cephalometric measurements. ${ }^{17}$

Early orthodontic treatment in children, if started at the optimal maturation stage, can give the best results with the lowest predictable probability of treatment failure. ${ }^{2}$ Early orthodontic treatment performed in skeletal cases with growth modification usually used of orthodontic functional appliances. The used orthodontic functional appliances at the peak in pubertal growth can accelerate the expected success of the treatment was twice more effective than carried out three years before or three years after the peak. ${ }^{13}$

\section{CONCLUSION}

There was a difference in anteroposterior dimensions of the maxillary and mandibular in cervical vertebral maturation in children with intermediate mixed and early permanent dentition, however, no difference was found in the 
anterior cranial base.

\section{REFERENCES}

1. Proffit WR, Fields HW, Sarver DM. Contemporary Orthodontics. $5^{\text {th }}$ ed. St. Loius: Mosby Elsevier. 2013. p. 19-109.

2. Chandrasekar R, Chandrasekhar S, Sundari KKS, Ravi P. Development and validation of a formula for objective assessment of cervical vertebral bone age. Progress in Orthodontics. 2020; 21(38). DOI: 10.1186/s40510-02000338-0

3. Dhiman S, Maheshwari S, Verma SK. Assessment of maturity in orthodontics: A review. Journal of Advanced Clinical \& Research Insights. 2015; 2(2):100-3. DOI: 10.15713/ins.jcri.54

4. Perinetti G, Contardo L, Gabrieli P, Baccetti $\mathrm{T}$, Lenarda RD. Diagnostic performance of dental maturity for identifification of skeletal maturation phase. Europ J Orthod. 2012;34:487-492. DOI:10.1093/ejo/cjr027

5. McNamara JA, Lorenzo Franchi L. The cervical vertebral maturation method: A user's guide. Angle Orthod. 2018; 88(2):133-43. DOI: 10.2319/111517-787.1

6. Franchi L, Nierib M, Lomonacoc I, McNamara Jr JA, Giuntini V. Predicting the mandibular growth spurt: The roles of chronological age, sex, and the cervical vertebral maturation method. Angle Orthod. 2021; 91(3):307-312. DOI: 10.2319/080220-676.1

7. Kumar S, Singla A, Sharma R, Virdi MS, Anupam A, Mittal B. Skeletal maturation evaluation using mandibular second molar calcification stages. Angle Orthod. 2012; 82(3):501-506. DOI: $10.2319 / 051611-334.1$

8. Altan M, Dalcı ÖN, İșeri H. Growth of the cervical vertebrae in female from 8 to 17 years. A longitudinal study. Europ J Orthod. 2012;34:327-334. DOI: 10.1093/ejo/cjr013

9. Perinetti G, Rosso L, Riatti R, Contardo L. Sagittal and Vertical Craniofacial Growth Pattern and Timing of Circumpubertal Skeletal Maturation: A Multiple Regression Study. Hindawi Pub Corp BioMed Res Intern. 2016; DOI: $10.1155 / 2016 / 1728712$.

10. Mellion ZJ, Behrents RG, Johnston Jr LE. The pattern of facial skeletal growth and its relationship to various common indexes of Maturation. Am J Orthod Dentofacial
Orthop. 2013; 143(6):845-54. DOI: 10.1016/j. ajodo.2013.01.019

11. Perinetti G, Contardo L, CastaldoA, McNamara, Jr JA, Franchi L. Diagnostic reliability of the cervical vertebral maturation method and standing height in the identification of the mandibular growth spurt. Angle Orthod. 2016;86(4):599-609. DOI: 10.2319/072415$\underline{499.1}$

12. Perinetti G, Primozic J, Sharma B, Cioffi I, Contardo L. Cervical vertebral maturation method and mandibular growth peak: a longitudinal study of diagnostic reliability. European J Orthod. 2018; 40(6): 666-672. DOI: 10.1093/ejo/cjy018

13. Baysal A, Uysal T. Dentoskeletal effects of Twin Block and Herbst appliances in patients with Class II division 1 mandibular retrognathy. European J Orthod. 2014; 36:164-172. DOI: 10.1093/ejo/cjt013

14. Yin K, Han E, Guo J, Yasumura T, Grauer D, Sameshima G. Evaluating the treatment effectiveness and efficiency of Carriere Distalizer: a cephalometric and study model comparison of Class II appliances. Progress in Orthodontics. 2019; 20: 24. DOI: $10.1186 /$ s40510-019-0280-2

15. Jain M, Dhakar N. Timing of orthodontic treatment. J Orthod Res. 2013; 1(3): 99-102. DOI: $10.4103 / 2321-3825.123320$

16. Premkumar S. Textbook of Orthodontics. Reed Elsevier India. 2015; p.2-100.

17. Budiardjo SB, Karim AF, Indriati IS, Wahono NA, Suharsini M, Fauziah E, Rizal MF, Sutadi $H$. Length of anterior cranial base and Frankfort horizontal plane: A lateral cephalometric study in 11-16-year-old children. IOP Conf Series: J Physics: Conf Series. 2018. DOI: 10.1088/1742-6596/1073/2/022014

18. Afrand $M$, Ling $C P$, Khosrotehrani $S$, Flores-Mir $C$, Lagravère-Vich MO. Anterior cranial-base time-related changes: A systematic review. Am J Orthod Dentofacial Orthop. 2014; 146(1): 21-32. DOI: 10.1016/j.ajodo.2014.03.019

19. Soliman A, De Sanctis V, Elalaily R, Bedair $S$. Advances in pubertal growth and factors influencing it: Can we increase pubertal growth? Indian J Endocrinol Metab. 2014;18 (Suppl 1): S53-S DOI: 10.4103/2230$\underline{8210.145075}$ 
Differences of anteroposterior facial dimensions in male and female children on intermediate mixed (Listania et al.)

20. Zhao X-G, Lin J, Jiang J-H, Wang Q, NG $\mathrm{SH}$. Validity and reliability of a method for assessment of cervical vertebral maturation. Angle Orthod. 2012; 82(2): 229-34. DOI: 